\title{
Optimization of activation requirements of immature mouse dendritic JAWSII cells for in vivo application
}

\author{
LUKASZ ZAPALA $^{1}$, NADZIEJA DRELA ${ }^{2}$, JACEK BIL ${ }^{1}$, DOMINIKA NOWIS ${ }^{1}$, \\ GRZEGORZ W. BASAK ${ }^{3}$ and WITOLD LASEK ${ }^{1}$
}

\author{
${ }^{1}$ Department of Immunology, Centre of Biostructure, Medical University of Warsaw, Banacha 1a Street, F Building; \\ ${ }^{2}$ Department of Immunology, Faculty of Biology, Warsaw University, Miecznikowa 1 Street; ${ }^{3}$ Department of Hematology, \\ Oncology and Internal Medicine, Medical University of Warsaw, Banacha 1a Street, 02-097 Warsaw, Poland
}

Received August 23, 2010; Accepted November 12, 2010

DOI: $10.3892 /$ or. 2010.1128

\begin{abstract}
Dendritic cells (DCs) are specialized antigenpresenting cells that are present in peripheral tissues in a resting (immature) state. Their activation is a critical step in the initiation of the primary immune response. In the present study, we optimized in vitro conditions for maturation of commercially available immortalized mouse dendritic precursor JAWSII cells. These cells express surface markers and have properties that are typical of immature DCs and macrophages (e.g. MHC class I and II markers, CD80 molecules, high endocytic capacity), as well as TLR1, TLR3, TLR4, TLR6, and TLR7 receptors. When stimulated with poly I:C (and also LPS) JAWSII cells produced large amounts of IL-6, TNF- $\alpha$ and MCP-1. Incubation of JAWSII cells with IFN- $\gamma$ markedly increased expression of MHC class I molecules and, more importantly, combination of this cytokine with poly I:C significantly increased expression of CD40 surface protein and CD11c, the most characteristic marker of mouse DCs. The combination of both agents also inhibited the endocytic abilities of JAWSII cells. In in vivo migration studies, exposure of JAWSII cells to poly I:C and IFN- $\gamma$ led to increased accumulation of these cells in regional lymph nodes. Functional in vivo studies showed that tumor cell lysate-pulsed and subsequently poly I:C/IFN- $\gamma$-stimulated JAWSII cells promoted development of specific $\mathrm{T}$ cells in lymph nodes. Our studies show that the combination of optimal endogenous and exogenous ligands may induce phenotypic and functional maturation of JAWSII cells necessary for the accomplishment of their antigen-presenting function in vivo.
\end{abstract}

Correspondence to: Dr Witold Lasek, Department of Immunology, Centre of Biostructure, Medical University of Warsaw, Banacha 1a Street, F Building, 02-097 Warsaw, Poland

E-mail: witold.lasek@wum.edu.pl

Key words: dendritic cells, immunostimulators, JAWSII cell line

\section{Introduction}

Dendritic cells (DCs) have been shown to be the most important family of professional antigen presenting cells (APCs) orchestrating $\mathrm{T}$ cell immune response $(1,2)$. They are divided, regarding maturation stage, into the two major populations: immature and mature DCs $(1,3)$. In the absence of inflammatory or microbial stimulus, the majority of DCs found in tissues and lymphoid organs have a resting immature phenotype characterized by strong endocytic abilities and low expression of MHC class II molecules and costimulatory CD80/CD86 and CD40 molecules. Following contact with microbial elements in the presence of inflammatory mediators, such as proinflammatory cytokines, they acquire a mature phenotype $(4,5)$. At this stage, due to a high expression of MHC and costimulatory molecules and appropriate cytokine secretion profile, DCs are very efficient in $\mathrm{T}$ cell priming $(6,7)$.

Recognition of antigen in the absence of proper costimulation signal leads to the impaired activation of cytotoxic $\mathrm{T}$ lymphocytes (CTL) and, in fact, may induce the opposite effect, development of regulatory cells and tolerance $(1,8,9)$. Therefore, in the context of therapeutic application of DCs in the treatment of cancer in humans, the critical question is how to achieve the optimal maturation of DCs $(10,11)$. Other problems concerning the use of dendritic cells in the clinics include: limited number of DCs, which can be generated from monocytes isolated from a patient, contaminating cells in the DC preparation, which could affect the efficacy of DC vaccination, and variability of DCs in terms of their differentiation and their ability to induce cytotoxic $\mathrm{T}$ lymphocytes $(2,12,13)$. Moreover, a significant interindividual variability in response of DCs have been observed despite the identical stimulation procedure (14).

To circumvent these limitations, there have been attempts to establish cell lines that would be able to differentiate into antigen-presenting cells (15-17). JAWSII cells are bone marrow-derived cells that were isolated from p53-deficient mice $(18,19)$. These cells can survive in long-term cultures in the presence of GM-CSF and were found to express both macrophage- and dendritic cell-associated surface molecules (18). The aim of the present studies was to characterize 
phenotypic and functional potential of the JAWSII cells in order to use them in tumor immunotherapeutic models.

\section{Materials and methods}

Cells. JAWSII, an immortalized C57BL/6 murine bone marrow-derived DC line was purchased from American Type Culture Collection (CRL-11904). The cells were grown in RPMI-1640 medium (Sigma-Aldrich, St. Louis, MO, USA) supplemented with $10 \%$ non-inactivated FCS (GibcoInvitrogen, Paisley, Scotland, UK), antibiotics (penicillin + streptomycin + amphotericin, Sigma-Aldrich), and $5 \mathrm{ng} / \mathrm{ml}$ murine GM-CSF (PeproTech, London, UK). JAWSII cells were maintained in humidified atmosphere at $37^{\circ} \mathrm{C}$ and $5 \%$ $\mathrm{CO}_{2}$ and passaged twice a week.

Immunostimulators and cytokines. The following immunomodulators were used in the studies: lipopolysaccharide (LPS from E coli 055:B5, Sigma-Aldrich, concentration in cultures, $2 \mu \mathrm{g} / \mathrm{ml}$ ), polyriboinosinic polyribocytydylic acid (poly I:C sodium salt, Sigma-Aldrich, concentration in cultures, $100 \mu \mathrm{g} /$ $\mathrm{ml}$ ), oligodeoxynucleoitide 1826 (ODN 1826, Invivogen, San Diego, CA; concentration in cultures, $5 \mu \mathrm{g} / \mathrm{ml}), \mathrm{TNF}-\alpha$ (recombinant mouse TNF- $\alpha, E$. coli-derived, R\&D Systems, $10 \mathrm{ng} / \mathrm{ml}$ in cultures), interleukin-4 (murine IL-4, BD Pharmingen; $10 \mathrm{ng} / \mathrm{ml}$ in cultures), interferon $\gamma$ (recombinant mouse IFN- $\gamma$, BD Pharmingen, $10 \mathrm{ng} / \mathrm{ml}$ in cultures).

Mice. C57BL/6 mice (8-week-old, bred in a local animal facility and kept in conventional conditions) were used in in vivo experiments. The experiments were approved by the local ethics committee.

Flow cytometric analysis of JAWSII cell phenotype. The following monoclonal antibodies were used to study surface markers of JAWSII cells: anti-MHC class I (FITC conjugated mouse anti-mouse $\mathrm{H}-2 \mathrm{~K}^{\mathrm{b}}$, clone AF6-88.5), anti-MHC class II (FITC mouse anti-mouse I-A ${ }^{\mathrm{b}}$, clone AF6-120.1), anti-CD11c (FITC hamster anti-mouse CD11c, clone HL3), anti-CD40 (FITC hamster anti-mouse CD40, clone HM40-3), anti-CD80 [FITC hamster anti-mouse CD80 (B7-1), clone 16-10A1], and F4/80 (FITC rat anti-mouse F4/80); isotype-matched controls: FITC rat $\operatorname{IgG}_{1}, \kappa$ isotype control, FITC mouse $\operatorname{IgG}_{2 \mathrm{a}}$, $\kappa$ isotype control, FITC hamster $\operatorname{IgG}_{1}, \kappa$ isotype control. All but F4/80 were purchased from BD Biosciences- Pharmingen. F4/80 mAb was purchased from Serotec Ltd., UK. Anti-mouse polyclonal antibody (pAb) to TLR1 (rabbit) was purchased from Assay Designs, Inc. (Ann Arbor, MI); anti-mouse pAbs to TLR2 (rabbit) and TLR6 (rabbit) were purchased from Imgenex (San Diego, CA, USA) and anti-mouse pAb to TLR4 (rabbit) was provided by Invitrogen, Carlsbad, CA. Secondary antibodies for anti-TLR1, 2, 4 and 6 (FITC donkey anti-rabbit) were purchased from Invitrogen. Surface markers were analyzed either after 24 or $48 \mathrm{~h}$ incubation with immunostimulators at concentrations described in the previous section. Cells were collected, resuspended in PBS with $0.5 \%$ BSA and $0.05 \%$ sodium azide $(0.5$ million cells in $50 \mu \mathrm{l})$, incubated for $30 \mathrm{~min}$ at $4^{\circ} \mathrm{C}$ with appropriate mAbs, and analysed on FACSCalibur (Becton Dickinson). In case of anti-TLR1, 2, 4 and 6 staining, additional $30-\mathrm{min}$ incubation at $4^{\circ} \mathrm{C}$ with FITC secondary antibodies after washing cells in ice-cold PBS was necessary prior to FACS-Calibur analysis, while cells with only secondary antiobody added served as a negative control. The level of surface marker expression, estimated by the fluorescence intensity (FI), was analysed using CellQuest software.

Endocytosis assay. Fluorescein-conjugated dextran (FITC-DX 70,000 , Fluka, BioChemica) was used for the endocytosis assay. The ability of cells to endocytose FITC-DX (a method used to determine a highly selective, receptor-mediated antigen uptake mechanism) was measured as follows. JAWSII cells $\left(2 \times 10^{5}\right)$ were cultured in $1 \mathrm{ml}$ of medium in a 24 -well plate with addition of immunostimulators for $48 \mathrm{~h}$. Then the cells were treated with FITC-DX $(2 \mathrm{mg} / \mathrm{ml})$ for $50 \mathrm{~min}$ at $37^{\circ} \mathrm{C}$ to measure active endocytosis or at $4^{\circ} \mathrm{C}$ to determine background levels of endocytosis (negative control). At the end of the incubation, the cells were collected and washed 3 times by centrifugation at $4^{\circ} \mathrm{C}$ in PBS $(5 \mathrm{~min}, 300 \mathrm{x} \mathrm{g})$ and resuspended in $0.5 \mathrm{ml}$ of ice-cold PBS with $0.5 \% \mathrm{BSA}$ and $0.05 \%$ sodium azide for FACS analysis.

Cytokine secretion in cultures of JAWSII cells. JAWSII cells $\left(2 \times 10^{5}\right)$ were cultured in $1 \mathrm{ml}$ of culture medium in a 24-well plate for $24 \mathrm{~h}$. Next, the cells were incubated in the presence or absence of immunomodulatory agents (at concentrations described in the section, Immunostimulators and cytokines) for additional $24 \mathrm{~h}$. Then the culture supernatants were collected, centrifugated and frozen $\left(-20^{\circ} \mathrm{C}\right)$ prior to analysis of cytokine concentrations. The BD ${ }^{\mathrm{TM}}$ Cytometric Bead Array (CBA) Mouse inflammation kit (BD Biosciences) was used to quantitatively measure levels of interleukin 6 (IL-6), interleukin 10 (IL-10), monocyte chemoattractant protein 1 (MCP-1), interferon- $\gamma$ (IFN- $\gamma$ ), tumor necrosis factor $\alpha$ (TNF- $\alpha$ ), and interleukin 12p70 (IL-12p70) in the samples of culture supernatant. Concentrations of cytokines in supernatants were measured according to the instruction manual provided by the manufacturer, using FACSCalibur and the BD CBA analysis software.

Expression of Toll-like receptors (TLRs) - Western blotting. Anti-mouse polyclonal antibody (pAb) to TLR3 (rabbit) was purchased from Assay Designs, Inc. (Ann Arbor, MI); antimouse pAb to TLR7 (rabbit) was provided by BD BiosciencesPharmingen and anti-mouse monoclonal antibody (mAb) to TLR9 (mouse) was purchased from Imgenex. JAWSII cells were cultured for $24 \mathrm{~h}$ in 100 x 20 -mm dishes $\left(10^{6}\right.$ cells in $10 \mathrm{ml}$ ) and then immunomodulatory agents were added for additional $24 \mathrm{~h}$ at the concentrations described in the section, Immunostimulators and cytokines. At the end of the incubation, the cells were collected and washed in ice-cold PBS 2 times. Then the pellets were lysed with RIPA buffer (RadioImmunoPrecipitation Assay Buffer, $200 \mu \mathrm{l}$ ) containing $50 \mathrm{mM}$ Tris base, $150 \mathrm{mM} \mathrm{NaCl}, 1 \% \mathrm{NP}-40,0.25 \%$ sodium deoxycholate and $1 \mathrm{mM}$ EDTA (all from Sigma-Aldrich) supplemented with protease inhibitors (Inhibitor Cocktail, Roche, $20 \mu \mathrm{l}$ ) and phosphatase inhibitors (Inhibitor Cocktail, Roche, $2 \mu 1$ ). Protein concentrations were measured using BioRad Protein Assay. The samples were mixed with sample buffer and boiled for 5 min. Standard 10\% sodium dodecyl sulfate-polyacrylamide gels (SDS-PAGE) were run, loading 
MHC I

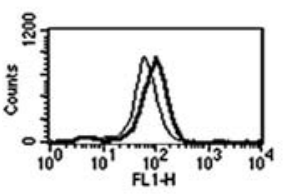

CD40
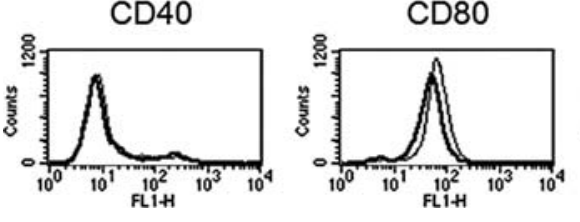

CD11c
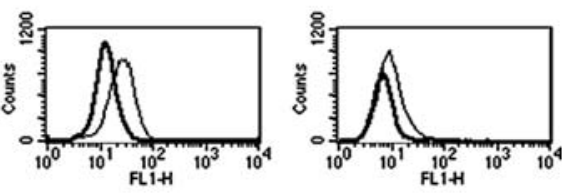

$\mathrm{F} 4 / 80$

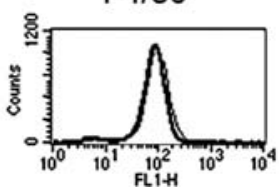

Figure 1. Expression of MHC class I and II molecules and CD11c, CD40 CD80, and F4/80 markers on adherent (thick line) and non-adherent (thin line) JAWSII cells. The cells, either adherent or non-adherent, were selected during three consecutive passages. For clarity, isotype control profiles were omitted.

approximately $20 \mu \mathrm{g}$ protein in each lane and then electrophoretically blotted onto the Protran ${ }^{\circledR}$ nitrocellulose membrane (Schleicher \& Schuell BioScience Inc., Keene, NH). The membrane was then soaked in a blocking solution: TBST [Tris-buffered saline ( $\mathrm{pH} 7.4)$ and $0.05 \%$ Tween-20] supplemented with $5 \%$ nonfat milk and $5 \%$ fetal bovine serum for $1 \mathrm{~h}$ at room temperature. After extensive washing with TBST, the soaked membrane was incubated with appropriate primary antibody overnight at $4^{\circ} \mathrm{C}$. To normalize protein loading, the membrane was at first incubated with rabbit polyclonal antibody against either $\alpha$-tubulin or $\beta$-actin (Calbiochem, San Diego, CA, USA), followed by the incubation with donkey anti-rabbit antibody conjugated with alkaline phosphatase (AP) (ImmunoPure ${ }^{\circledR}$ Antibody, Pierce Biotechnology, Inc., Rockford, IL) and visualized using 1-Step NBT/BCIP Reagent (Pierce Biotechnology, Inc.). Finally, the blots were stained using appropriate pAbs to TLRs (or mAb to TLR9), followed by donkey anti-rabbit or goat anti-mouse antibody conjugated with AP (ImmunoPure Antibody, Pierce Biotechnology, Inc.) and visualized using 1-Step NBT/BCIP Reagent (Pierce Biotechnology, Inc.).

In vivo JAWSII cell migration assay. Cells were labeled with the intracellular dye carboxy-fluoresceine diacetate succinimidyl ester (CFSE) $(10 \mu \mathrm{M})$. CFSE was added to the cell suspensions and the mixture was incubated for $20 \mathrm{~min}$ at $37^{\circ} \mathrm{C}$. The labeling reaction was stopped by repetitive washing with ice-cold PBS 2 times and the cells were suspended in PBS for injections. C57BL/6 mice (4 mice per group) were injected into the footpad of the right hind limb with one million JAWSII cells, either unstimulated or stimulated for $48 \mathrm{~h}$ prior to the injection into the footpad with poly $\mathrm{I}: \mathrm{C}(100 \mu \mathrm{g} / \mathrm{ml})$ and IFN- $\gamma(10 \mathrm{ng} / \mathrm{ml})$, alone or in combination. Two days after the injection of JAWSII cells, mice were sacrificed and the popliteal lymph nodes (LNs) were isolated. LNs were then digested with constant stiring in enzymic solution containing $0.25 \%$ collagenase (type I), $0.05 \%$ DNase, $17.5 \mu \mathrm{M} \mathrm{N \alpha -p-}$ tosyl-l-lysine chloromethyl ketone (TLCK) and $1 \%$ antibioticantimycotic solution (all from Sigma-Aldrich) in F-12 medium (Gibco BRL, Paisley, Scotland UK) for $\sim 2 \mathrm{~h}$ at $37^{\circ} \mathrm{C}$. Following isolation, LN cells were filtered through a $40 \mu \mathrm{m}$ mesh nylon filter, rinsed 3 times with PBS, resuspended in $0.5 \mathrm{ml}$ of ice-cold PBS with $0.5 \% \mathrm{BSA}$ and $0.05 \%$ sodium azide for FACS analysis. To define the number of JAWSII cells in the cell suspension, CFSE-labeled JAWSII cells from in vitro culture were mixed with $\mathrm{LN}$ cells prepared from mice injected with PBS and the gate was created confining strongly fluorescing cells.

Ability of JAWSII cells to induce specific antitumor response. B78-H1 melanoma cells (23) suspended in PBS at a concentration of one million cells in $250 \mu 1$ were frozen rapidly in liquid nitrogen to lyse the cells. Next, the lysed cells were sonificated using UP100H Ultrasonic processor (Hielscher) in 3 cycles, each lasting $10 \mathrm{sec}$, centrifuged, and then the supernatants were added to JAWSII cell cultures (B78-H1 lysates, JAWSII cells ratio 1:1). The cells were pulsed for $3 \mathrm{~h}$ and next the cultures were stimulated with poly I:C $(100 \mu \mathrm{g} / \mathrm{ml})$ and IFN- $\gamma(10 \mathrm{ng} / \mathrm{ml})$, either alone or in combination, or left untreated. After $48 \mathrm{~h}$ of incubation, JAWSII cells were collected, washed in PBS, and C57BL/6 mice were injected into the footpad of the right hind limb with one million JAWSII cells in $20 \mu 1$ of PBS (3 mice per group, control group was treated with PBS). After 7 days, mice were sacrificed, regional popliteal LNs were separated, and LN cells were prepared as described in the previous section. To determine specific antitumor activation of LN lymphocytes, $\gamma$-irradiated (4,500 Rads) B78-H1 cells were plated in a flat-bottom 96-well plate ( $2 \times 10^{4}$ cells in $100 \mu 1$ culture medium) for $3 \mathrm{~h}$ and then $2 \times 10^{5} \mathrm{LN}$ cells (in $100 \mu \mathrm{l}$ ) were added to each well. After $24 \mathrm{~h}$ of cocultivation, culture supernatants were harvested $(n=8$ for each group) and the amount of IFN- $\gamma$ was measured using ELISA (DuoSet ELISA development system kit, R\&D System Europe Ltd.).

Statistical analysis. The Kolmogorov-Smirnov statistic was used to evaluate changes in the expression of surface markers. The most representative results are presented on histograms. Differences between concentrations of cytokines in supernatants from JAWSII cell cultures stimulated with cytokines or exogenous ligand were analyzed using Mann-Whitney U test.

\section{Results}

Phenotypic characterization of resting JAWSII cells. The cultures of JAWSII cells consisted of a heterogeneous mixture of loosely adherent cells; most adhered but with time some cells detached and grew in suspension. To determine whether these two populations constituted separate subpopulations or represented different stages of maturation, membrane molecules typical for dendritic cells (CD11c, CD40, CD80, MHC I and II molecules), as well as F4/80 marker were examined on the cells that were selected by three passages from either adherent or non-adherent population. As shown in Fig. 1, JAWSII cells are characterized by high expression of MHC class I, F4/80 and CD80 molecules, moderate/low expression of MHC class II molecules, and low or lack expression of CD11c marker and CD40 molecule on the surface. The cells, which were selected to grow in suspension, expressed slightly higher expression of CD11c and MHC class II molecules and represented probably the same 
A

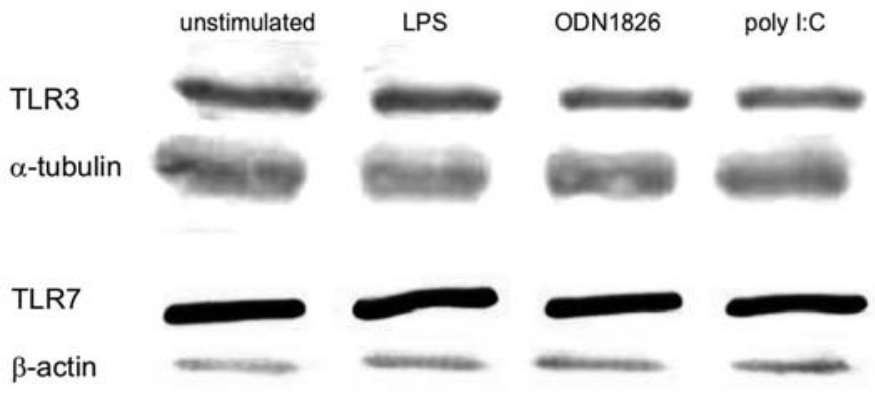

TLR9

$\alpha$-tubulin

B
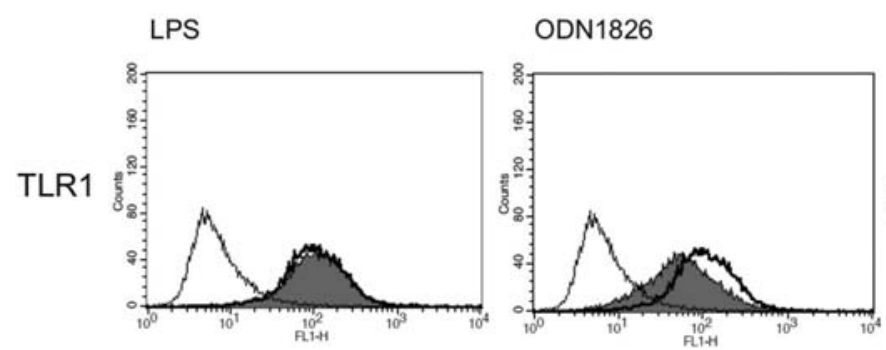

poly I:C

LPS

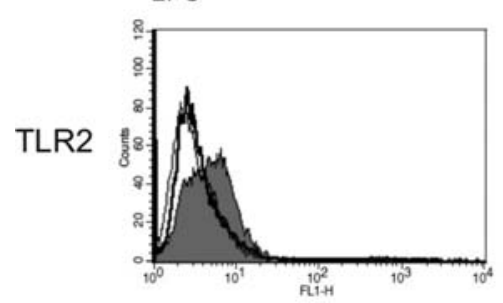

LPS

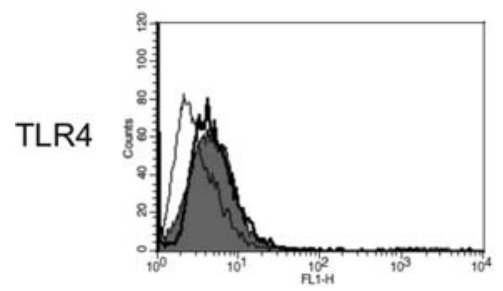

LPS

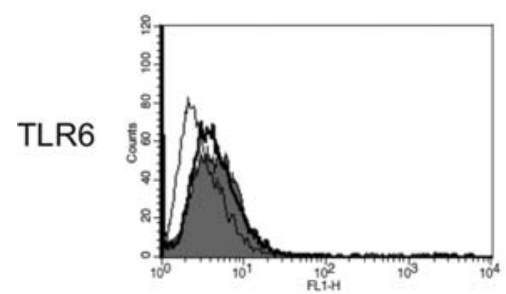

ODN1826

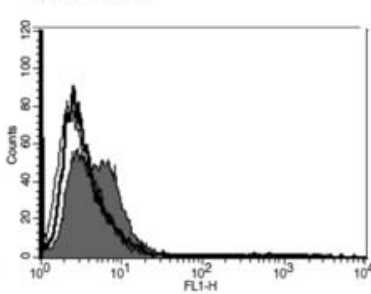

ODN1826

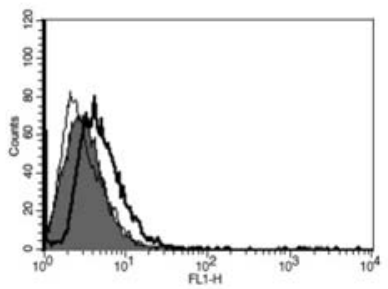

ODN1826

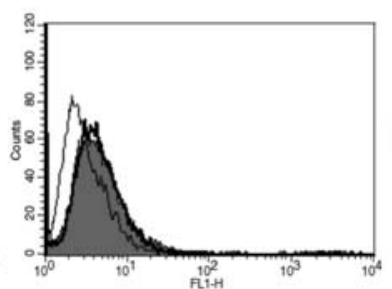

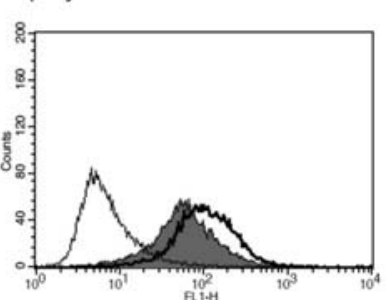

poly I:C

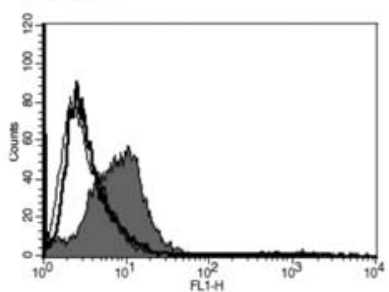

poly I:C

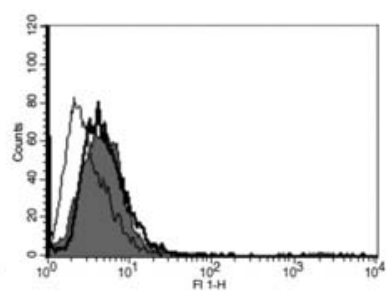

poly I:C

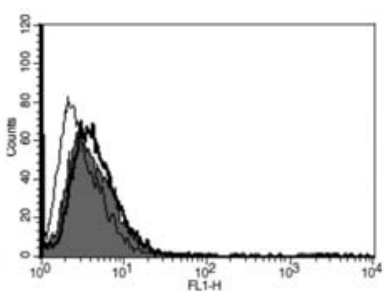

Figure 2. (A) Toll-like receptor expression (TLR3, TLR7 and TLR9) in JAWSII cells incubated for $24 \mathrm{~h}$ in the absence or presence of LPS (2 $\mu \mathrm{g}$ ), ODN 1826 $(5 \mu \mathrm{g} / \mathrm{ml})$ or poly I:C $(100 \mu \mathrm{g} / \mathrm{ml})$. Western blot analysis was performed as described in Materials and methods. (B) FACS analysis of surface expression of TLR1, TLR2, TLR4 and TLR6 on JAWSII cells either unstimulated or incubated with LPS, ODN 1826 or poly I:C. Filled histograms represent specific staining of stimulated cells. Relevant isotype controls are shown as thin lines and specific staining of unstimulated cells is presented as thick lines. 

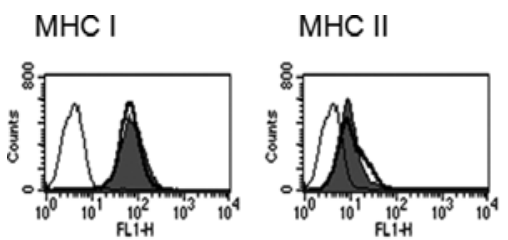

CD11c
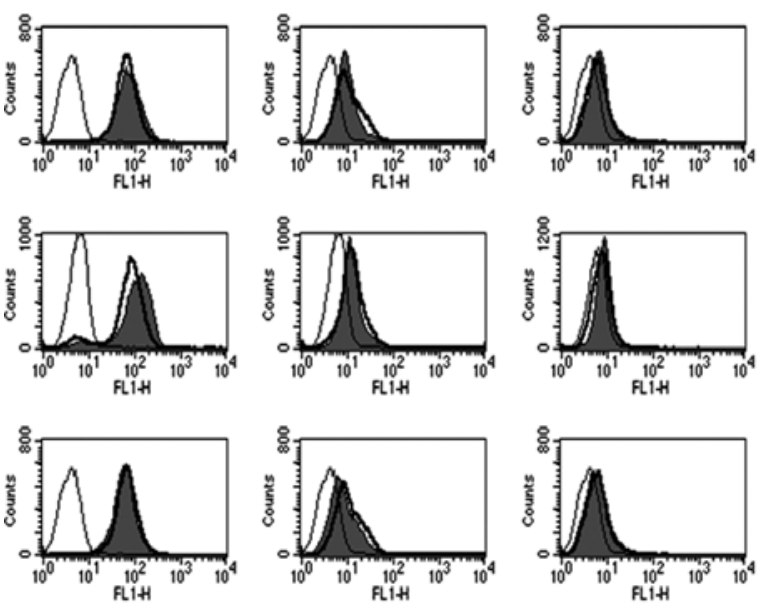
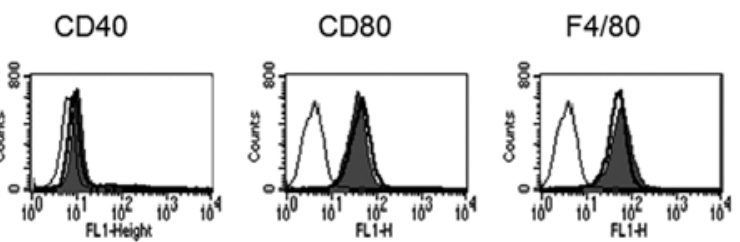

LPS
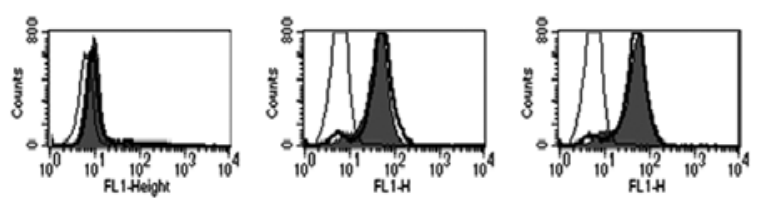

poly I:C
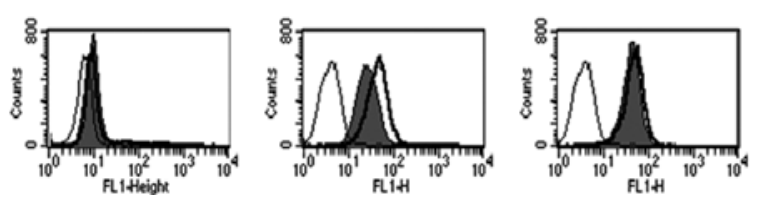

ODN 1826

Figure 3. Expression of MHC class I and II molecules and CD11c, CD40, CD80, and F4/80 markers on JAWSII cells stimulated with LPS (2 $\mu$ g/ml), poly I:C $(100 \mu \mathrm{g} / \mathrm{ml})$ or ODN $1826(5 \mu \mathrm{g} / \mathrm{ml})$. Filled histograms represent specific staining of stimulated cells. Relevant isotype controls are shown as thin lines and specific staining of unstimulated cells is presented as thick lines. JAWSII cells were incubated with appropriate immunostimulators for $24 \mathrm{~h}$, followed by washing and immunostaining as described in Materials and methods.
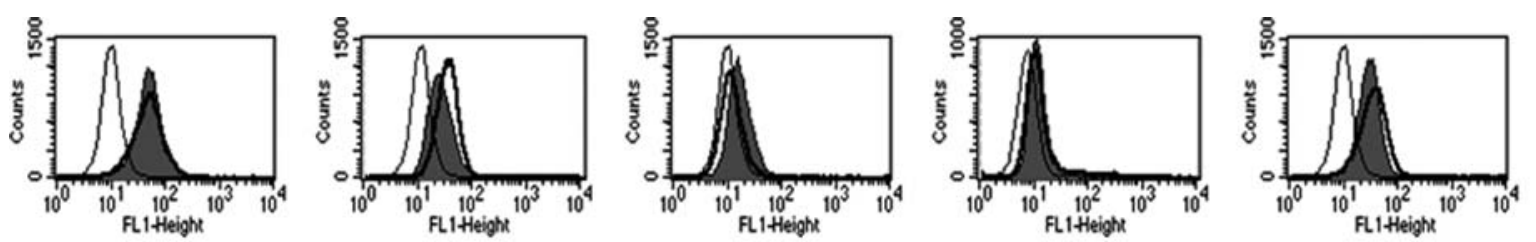

TNF- $\alpha$
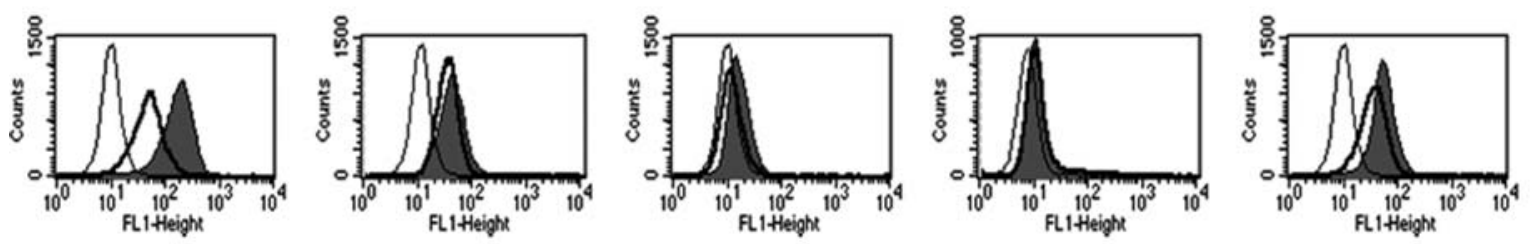

IFN-Y

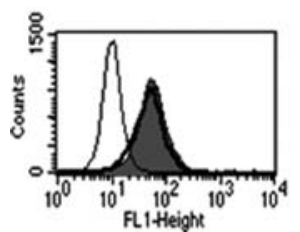

$\mathrm{MHC}$ I

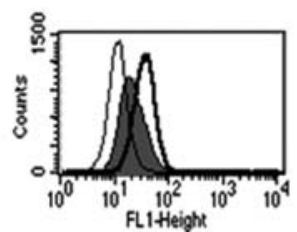

MHC II

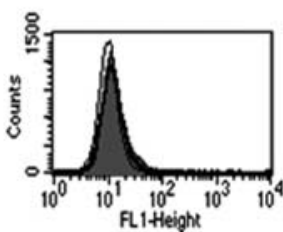

CD11c

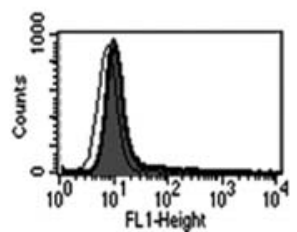

CD40

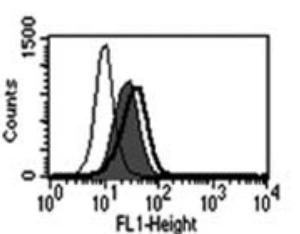

CD80

Figure 4. Phenotypic characteristics of JAWSII cells incubated with TNF- $\alpha$, IFN- $\gamma$ or IL-4. Filled histograms represent specific staining of stimulated cells. Relevant isotype controls are shown as thin lines and specific staining of unstimulated cells is presented as thick lines. The cells were cultured in the presence of TNF- $\alpha(10 \mathrm{ng} / \mathrm{ml}), \mathrm{IFN}-\gamma(10 \mathrm{ng} / \mathrm{ml})$ or IL-4 (10 ng/ml) for $24 \mathrm{~h}$, collected and immunostained as described in Materials and methods.

population as adherent cells but at the earlier stage of development or in the different phases of the cell cycle.

The next step was examination of the stability of the JAWSII cell line cultivated for prolonged time. The cells from early passages and JAWSII cells cultured for 7 weeks were compared. We found similar expression of CD11c, CD80 and MHC class I molecules on the cells. It was interesting that a smaller number of cells from prolonged cultures expressed MHC class II molecules and early cultures contained a proportion of $\mathrm{CD} 40^{+}$cells $(27 \%)$ with low fluorescence intensity (data not shown).

TLR expression in JAWSII cells. TLRs have recently emerged as a pivotal component of the innate immune system necessary for the detection of microbial elements, APC activation and the induction of adaptive immune response $(20,21)$. TLRs play a role in promoting dendritic cell maturation and their individual expression is dependent on the subset of dendritic cells $(21,22)$; thus, we decided to examine the presence of these receptors in JAWSII cells; either unstimulated or incubated with LPS, ODN 1826 [an oligodeoxynucleotide mimicking bacterial DNA with strong immunostimulatory properties in vivo (23)] or poly I:C. Using Western blot analysis we found high expression of TLR3 and TLR7, and undetectable expression of TLR9 in JAWSII cells (Fig. 2A). Amongst cell surface TLRs, FACS analysis revealed high expression of TLR1, moderate expression of TLR4 and TLR6 and the absence of TLR2 (Fig. 2B). Expression of TLR1 was decreased 
poly I:C
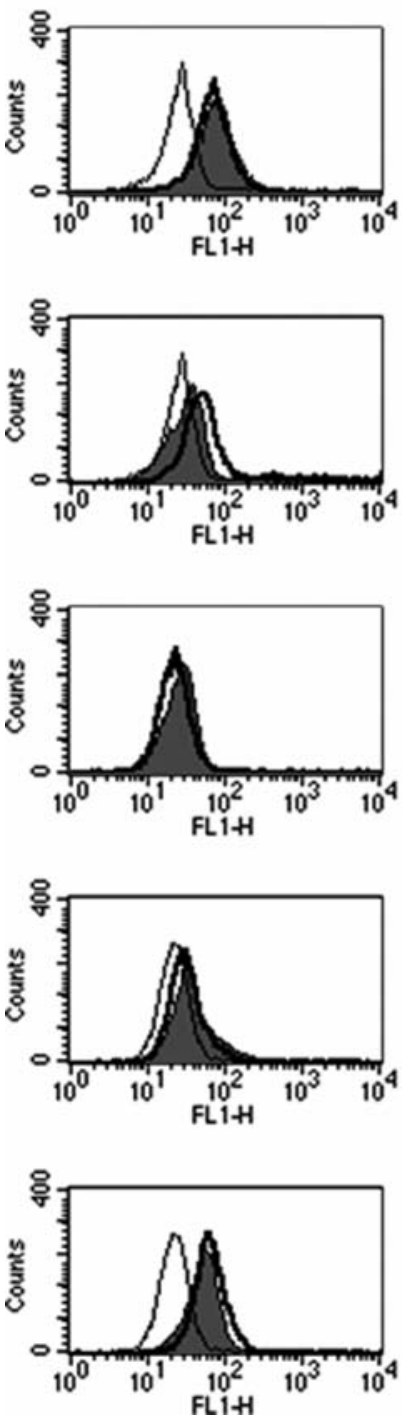

IFN-y
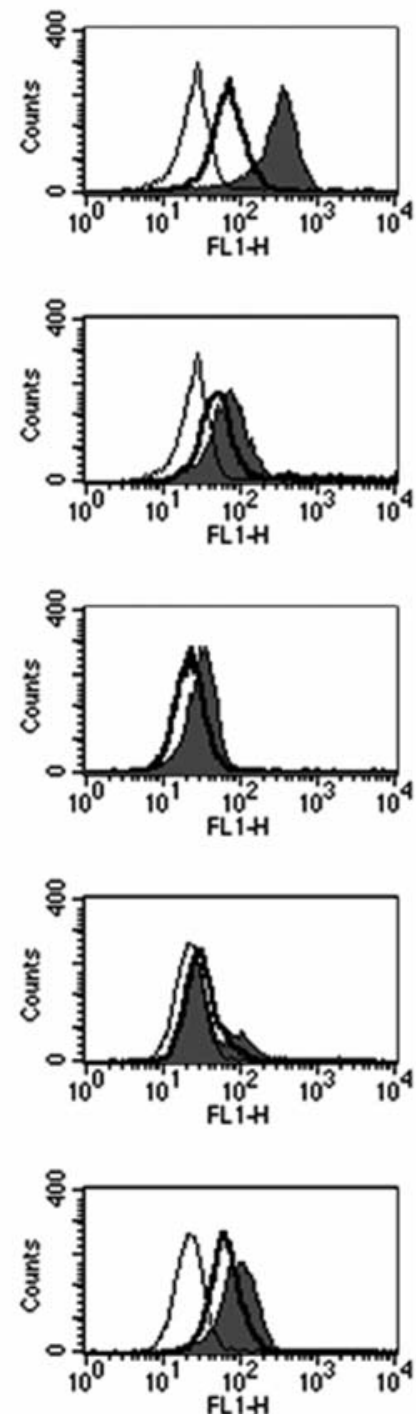

poly I:C + IFN-Y

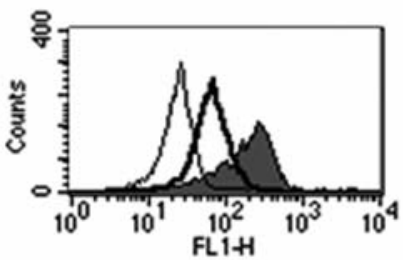

$\mathrm{MHC}$ I

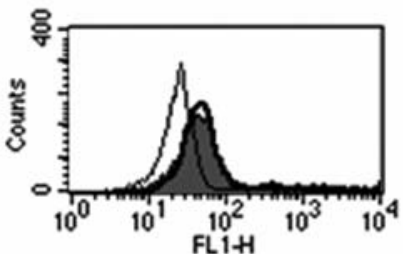

MHC II

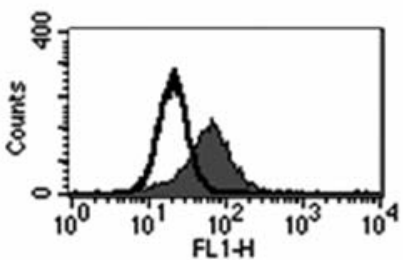

$\mathrm{CD} 11 \mathrm{c}$

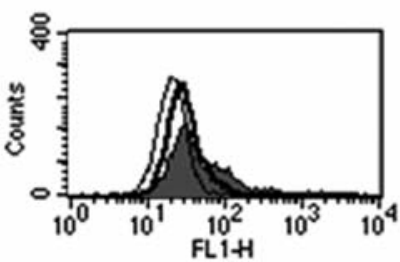

CD40

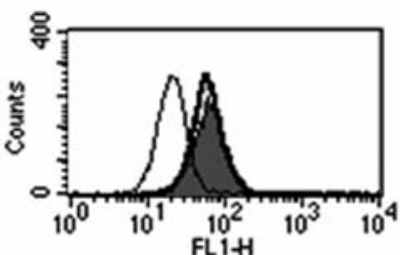

CD80

Figure 5. Expression of MHC class I and II molecules and CD11c, CD40, and CD80 markers on JAWSII cells stimulated with poly I:C (100 $\mu \mathrm{g} / \mathrm{ml})$ and/or IFN- $\gamma(10 \mathrm{ng} / \mathrm{ml})$. Filled histograms represent specific staining of stimulated cells. Relevant isotype controls are shown as thin lines and specific staining of unstimulated cells is presented as thick lines. JAWSII cells were incubated with appropriate immunostimulators for $48 \mathrm{~h}$, followed by washing and immunostaining as described in Materials and methods.

after incubation with ODN 1826 or poly I:C, while all three stimulators (LPS, ODN 1826 and poly I:C) induced expression of TLR2 (Fig. 2B).

Phenotypic analysis of stimulated JAWSII cells. Since the condition sine qua non of optimal function of DC is, apart from MHC molecules, enhanced expression of some costimulatory surface proteins, especially CD40 and CD80 $(3,24)$, we studied phenotypic changes of JAWSII cells after stimulation with selected exogenous ligands: LPS, poly I:C, and ODN 1826, as well as with cytokines: IL-4, TNF- $\alpha$, and IFN- $\gamma$. As shown in Fig. 3, none of the exogenous immunostimulators influenced significantly the expression of CD11c, CD40 and MHC II molecules. Poly I:C enhanced the expression of MHC I molecules, while ODN 1826 seemed to decrease the expression of CD80. On the other hand, IFN- $\gamma$ exerted significant stimulatory effect on the expression of CD80 and MHC class I molecules. This cytokine also enhanced slightly the expression of CD11c molecules, while no effect was observed on the level of CD40 and MHC class II (Fig. 4). Both TNF- $\alpha$ and IL-4 exerted either no or weak effect on the expression of the studied markers. In case of IL-4, the effect was, in fact, inhibitory for CD80 and MHC class II molecules (Fig. 4).

Next, we put the question, whether a combination of exogenous and endogenous immunomodulating agents could optimize the profile of surface molecule expression. Therefore, we decided to expose the cells to poly I:C + IFN- $\gamma$ and, taking into account that prolonged incubation of JAWSII cells is more optimal for expression of cell-membrane molecules (18), we cultured the cells for $48 \mathrm{~h}$. As shown in Fig. 5, combination of poly I:C + IFN- $\gamma$ strikingly increased expression of CD11c and, more importantly, was effective in increasing CD40 expression on JAWSII cells. In comparison with controls and cultures stimulated with poly I:C or IFN- $\gamma$, 

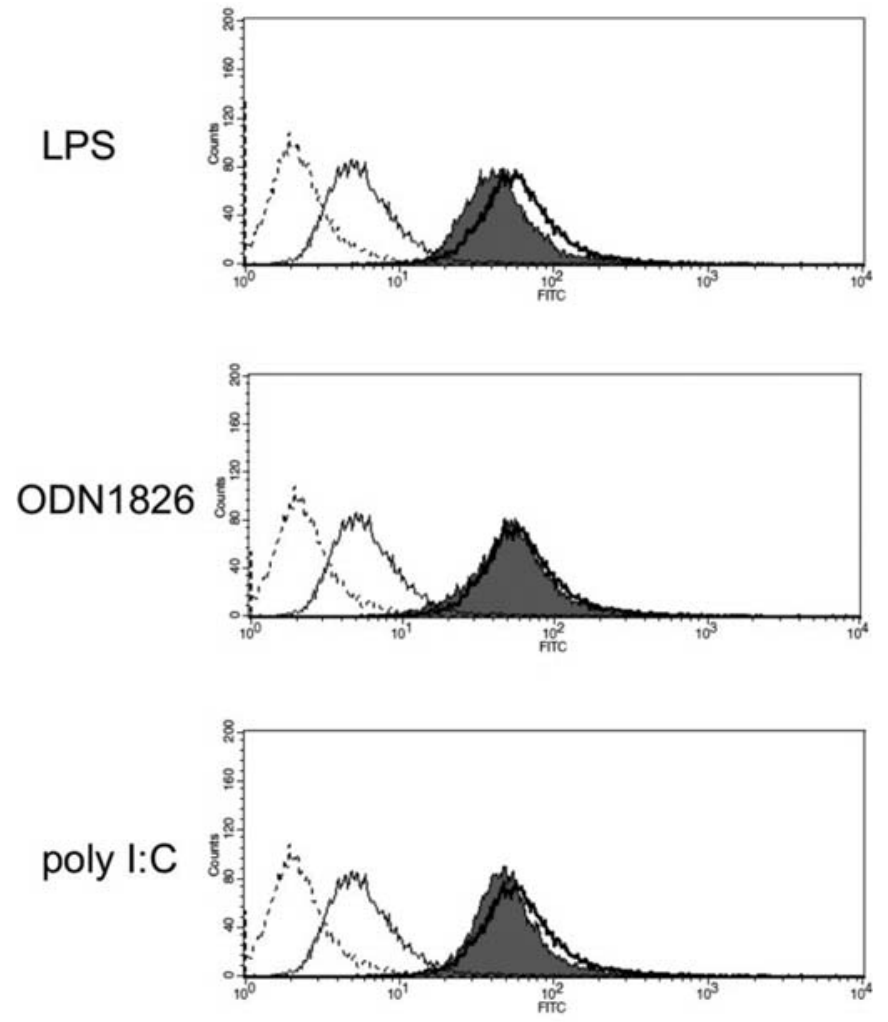

IFN- $\gamma$

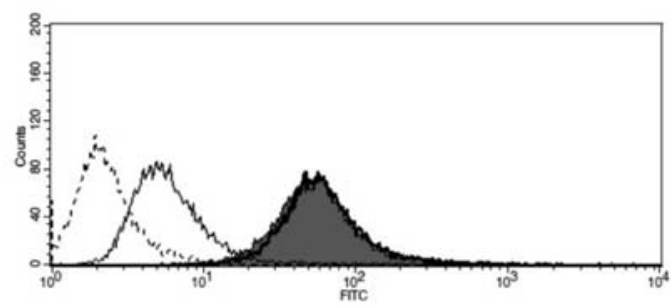

poly I:C $+\mathrm{IFN}-\gamma$

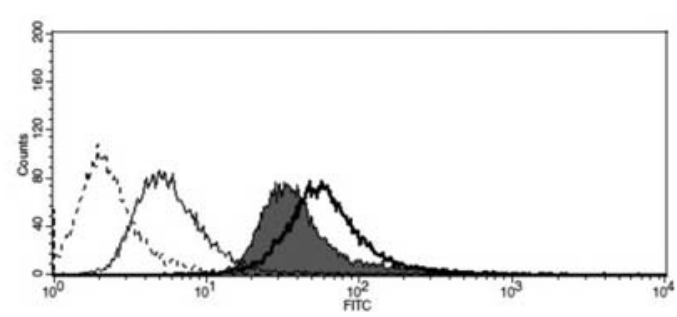

Figure 6. The effects of LPS, ODN 1826, poly I:C, IFN- $\gamma$ or combination of poly I:C and IFN- $\gamma$ on endocytic properties of JAWSII cells. The cells were stimulated with LPS $(2 \mu \mathrm{g} / \mathrm{ml})$, ODN $1826(5 \mu \mathrm{g} / \mathrm{ml})$, poly I:C $(100 \mu \mathrm{g} / \mathrm{ml})$ or IFN- $\gamma(10 \mathrm{ng} / \mathrm{ml})$ for $48 \mathrm{~h}$ and incubated for $50 \mathrm{~min}$ in $37^{\circ} \mathrm{C}$ with FITCDX as described in Materials and methods. Each graph shows negative control (unstained cells, dotted line), background level of endocytosis $\left(\mathrm{T}=4^{\circ} \mathrm{C}\right.$, thin line), FITC-DX uptake by unstimulated cells (thick line), and FITC-DC uptake by stimulated cells (filled histograms).

a significant proportion of the cells was characterized by high expression of CD40 (38\% vs. $15 \%, 25 \%$ and $26 \%$, respectively).

Endocytotic properties of JAWSII cells. The endocytic capacity of JAWSII cells, either unstimulated or incubated in the presence of LPS $(2 \mu \mathrm{g} / \mathrm{ml})$, ODN $1826(5 \mu \mathrm{g} / \mathrm{ml})$, poly I:C $(100 \mu \mathrm{g} / \mathrm{ml}), \mathrm{IFN}-\gamma(10 \mathrm{ng} / \mathrm{ml})$ or poly I:C $+\mathrm{IFN}-\gamma$ is
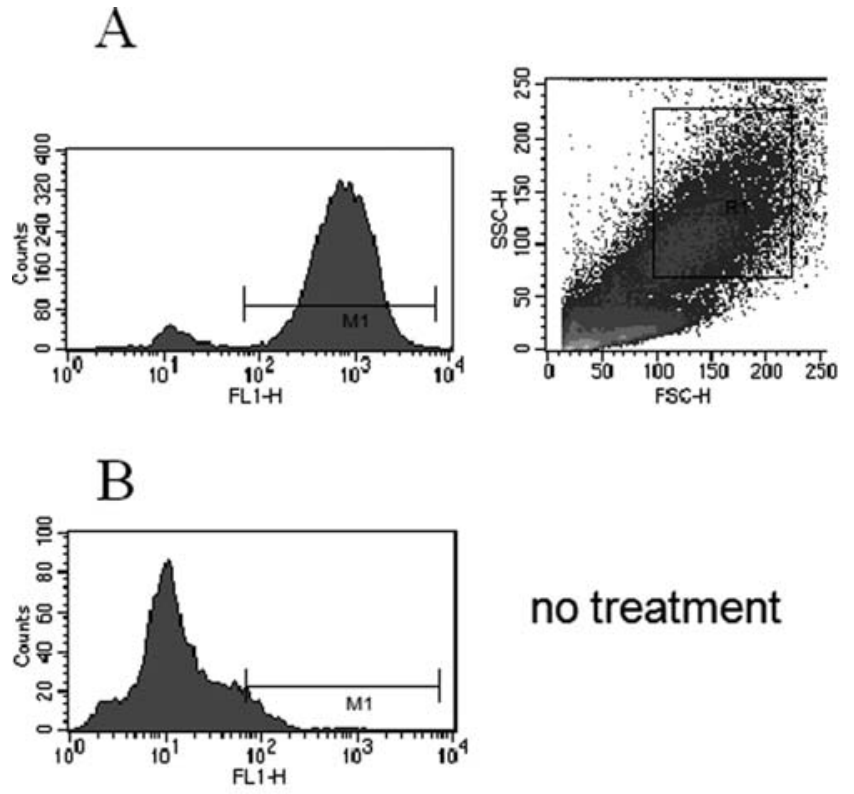

no treatment

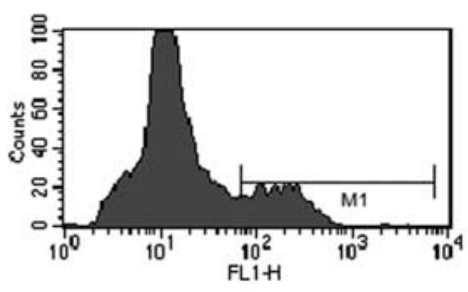

poly I:C

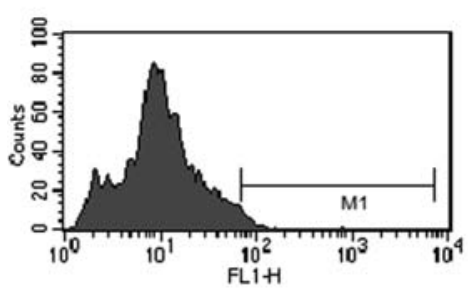

IFN-Y

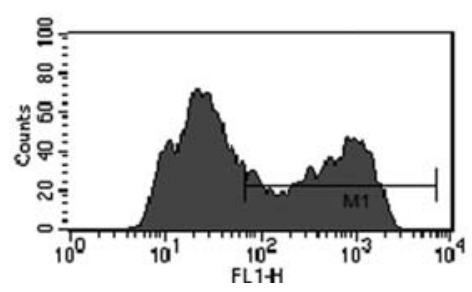

poly I:C + IFN-Y

Figure 7. Trafficking of JAWSII cells stimulated with poly I:C $(100 \mu \mathrm{g} / \mathrm{ml})$ and/or IFN- $\gamma(10 \mathrm{ng} / \mathrm{ml})$ to the regional lymph nodes. CFSE-labeled JAWSII cells were either stimulated with poly I:C \pm IFN- $\gamma$ or unstimulated for 2 days and one million cells was injected into the footpad of the right hind limb. Two days after the injection, mice were sacrificed, the popliteal lymph nodes were isolated, and suspensions of LN cells were prepared and analysed by FACS. To define JAWSII cells in the cell suspension, CFSElabeled JAWSII cells from in vitro culture were mixed with LN cells prepared from mice injected with PBS and the gate was created confining population of CFSE-labeled JAWSII cells (A). These cells are distributed within the M1 bars (B).

presented in Fig. 6. FITC-dextran tracer was effectively incorporated by unstimulated JAWSII cells. ODN $1826 \mathrm{did}$ not seem to influence on the endocytic properties, while incubation with LPS, or especially poly I: C + IFN- $\gamma$, markedly reduced endocytosis.

Secretion of cytokines. Unstimulated JAWSII cells produced small amounts of IL-6, TNF- $\alpha$ and chemokine MCP-1 and no 
Table I. Secretion of cytokines by JAWSII cells stimulated with LPS or poly I:C.

\begin{tabular}{|c|c|c|c|c|c|c|c|}
\hline \multirow[b]{2}{*}{ Stimulator } & \multirow[b]{2}{*}{$\mathrm{n}$} & \multicolumn{6}{|c|}{ Cytokine production in culture (pg/ml) (median) } \\
\hline & & IL-6 & IL-10 & IL-12 & TNF- $\alpha$ & IFN- $\gamma$ & MCP-1 \\
\hline LPS & 7 & $>5000^{\mathrm{b}}$ & 0 & 0 & $>5000^{c}$ & 0 & $3492^{\mathrm{a}}$ \\
\hline Poly I:C & 6 & $>5000^{b}$ & 0 & 0 & 2000 & 0 & 3510 \\
\hline None & 9 & 194 & 0 & 0 & 321 & 0 & 493 \\
\hline
\end{tabular}

JAWSII cells $\left(2 \times 10^{5}\right.$ in $\left.1 \mathrm{ml}\right)$ were plated in $24-$ well plates and after $3-4 \mathrm{~h}$ were exposed to LPS $(2 \mu \mathrm{g} / \mathrm{ml})$ or poly I:C (100 $\left.\mu \mathrm{g} / \mathrm{ml}\right)$. Supernatants were collected after $48 \mathrm{~h}$. Cytokine concentration was recognized as 0 when its amount in a sample was equal 0 or close to the lowest threshold of sensitivity of the assay; $n$, number of samples tested. ${ }^{a} \mathrm{p}<0.05,{ }^{b} \mathrm{p}<0.01,{ }^{c} \mathrm{p}<0.001$, in comparison with controls.

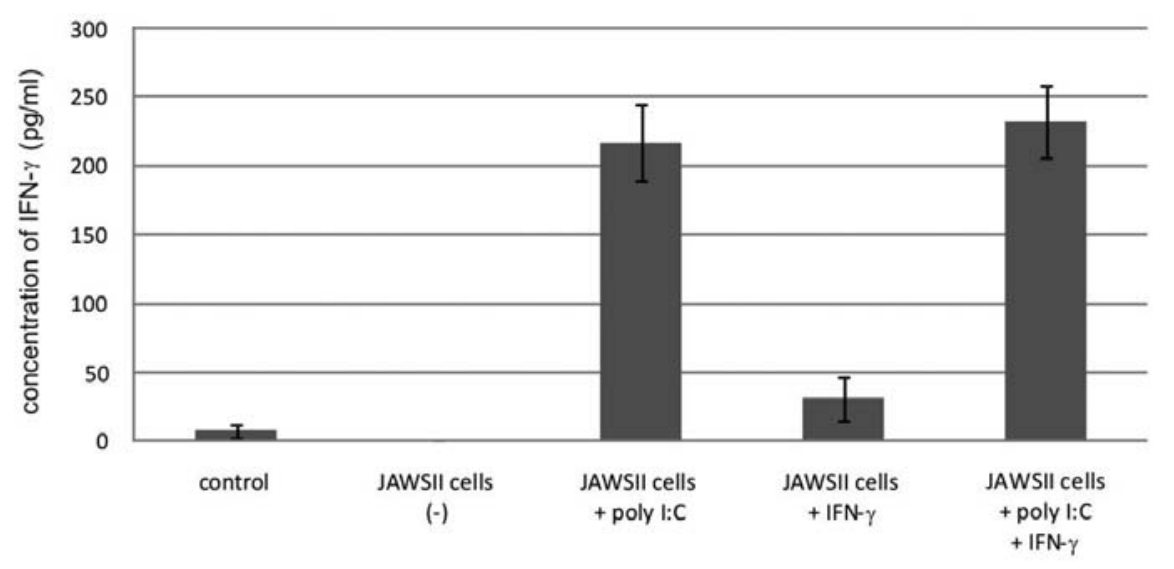

Figure 8. Production of IFN- $\gamma(\mathrm{pg} / \mathrm{ml})$ in cultures of regional LN lymphocytes from mice injected with JAWSII cells. Prior to the injections, JAWSII cells were pulsed with sonificated lysates of B78-H1 melanoma cells and incubated for $48 \mathrm{~h}$ with culture medium only, or stimulated with poly I:C \pm IFN- $\gamma$. Seven days after the injections of JAWSII cells, mice were sacrificed, the popliteal LNs were isolated and single-cell suspensions of lymphocytes were prepared. LN lymphocytes were restimulated with $\gamma$-irradiated B78-H1 cells for $24 \mathrm{~h}$ and the amount of IFN- $\gamma$ in culture supernatants was determined in ELISA.

IL-10, IL-12 and IFN- $\gamma$. Incubation of the cells with either LPS or poly I:C changed dramatically their ability to secrete cytokines. While again, like in the untreated cultures, no IL-10, IL-12 and IFN- $\gamma$ were produced after stimulation, the level of IL-6, TNF- $\alpha$ and chemokine MCP-1 in both LPS and poly I:Cstimulated JAWSII cell cultures reached the levels of several $\mathrm{ng} / \mathrm{ml}$ and even more than $5 \mathrm{ng} / \mathrm{ml}$ (Table I). It should be noted, however, that unstimulated JAWSII cells produced occasionally, from unknown reasons, high amounts of IL-6, TNF- $\alpha$ and chemokine MCP-1. In contrast, neither IFN- $\gamma$ nor TNF- $\alpha$ and IL-4 influenced significantly production of the six tested cytokines by JAWSII cells (data not shown).

Migration of JAWSII cells to regional lymph nodes. To study the capacity of JAWSII cells to migrate to a draining lymph node, poly I:C and/or IFN- $\gamma$-matured JAWSII cells (CFSElabeled) were injected into the footpad of the hind limb and, on the day 2 after the injection, popliteal lymph nodes (LNs) were isolated. We observed increased volumes of the isolated LNs following injection of poly I:C, alone or in combination with IFN- $\gamma$ (data not shown). As shown in Fig. 7, JAWSII stimulated with both poli I:C and IFN- $\gamma$ migrated to regional lymph nodes in much higher number than that stimulated with either poly I:C or IFN- $\gamma$. In LNs isolated from mice injected with double-stimulated JAWSII cells, these cells constituted $0.31 \%$ of all LN cells, while this parameter for poly I:C-stimulated cells was $0.07 \%$, for IFN- $\gamma$-stimulated cells $-0.01 \%$, and for unstimulated JAWSII cells - $0.03 \%$.

Assessment of stimulatory abilities of JAWSII cells. To determine the ability of JAWSII cells to stimulate naive T cells, JAWSII cells that were pulsed with the tumor lysate (B78-H1 melanoma cells) and subsequently incubated for 2 days with poly I:C \pm IFN- $\gamma$ were injected into footpads of mice. As shown in Fig. 8, significant amounts of IFN- $\gamma$ were produced in cultures of regional LN lymphocytes restimulated with irradiated B78-H1 melanoma cells in the 'poly I:C' or 'poly $\mathrm{I}: \mathrm{C}+\mathrm{IFN}-\gamma$ ' groups. JAWSII cells that were pulsed with the tumor lysate and incubated with IFN- $\gamma$ exerted low ability to activate specifically antitumor $\mathrm{T}$ cells (corresponding to low IFN- $\gamma$ production in cultures), and JAWSII cells incubated with neither poly I:C nor IFN- $\gamma$ were devoid of this ability.

\section{Discussion}

In the present study, we evaluated the effect of exogenous and endogenous ligands on the expression of some typical markers of dendritic cells and the function of JAWSII cells. These cells represent immature DCs and could be the candidate 
cell type for the use in immunization protocols, for example to induce antitumor immunity.

The current standard in DC preparation is generation of immature DCs from enriched monocytes cultured in the presence of GM-CSF and IL-4, followed by exposure to maturation cocktail consisting to TNF- $\alpha$, IL-1ß, IL-6 and $\mathrm{PGE}_{2}$ (2). However, this protocol is labor-intensive, timeconsuming and expensive. There are also suggestions that monocyte-derived myeloid DCs can express maturation markers without being able to prime T-cell response in vivo (4). In fact, optimal induction of clonal $\mathrm{CD}^{+}$and $\mathrm{CD}^{+} \mathrm{T}$ cell expansion, CTL activity and memory cells requires synergy between multiple immunostimulatory agonists $(4,7,25)$. Understanding the DC biology in the context of triggering the adaptive immunity, is continuously evolving, based on ongoing research (7). Certainly, JAWSII cells, easy to maintain and stable in long-term cultures, would be a valuable tool in this area.

Apart from JAWSII cells, there were some successive attempts to generate antigen-presenting dendritic cells in mice (3). For example, Shen et al established the DC2.4 dendritic cell line by superinfection of GM-CSF-transduced bone marrow cells with $m y c$ and raf oncogenes (16). Another antigen-presenting cell line, XS52 was established by Xu et al from newborn mouse epidermis (17). This dendritic cell line mimicking Langerhans cells, although useful in investigations of immune response mechanisms in the skin (26), requires specific culture conditions: supplementation of culture supernatants from the skin-derived stromal NS cell line. Another long-term homogeneous, growth factor-dependent DC population, known as D1 cells, was established by Winzler et al from mouse spleen (11). However, this cell line, similar to the previous one, was characterized by complex culture requirements (necessity of addition of 3T3 fibroblast supernatant to culture medium) and, in comparison with JAWSII cells, the rate of proliferation of D1 cells was much slower.

Since JAWSII cell line was established, several groups of investigators have used these dendritic cells in functional studies and immunization protocols (27-30). However, no authors performed experiments aimed at their stability in cultures and characterization of the pivotal for the function of JAWSII cells Toll-like receptors. Consequently, despite the fact that a number of stimulatory agents were used to activate JAWSII cells, e.g. cytokines (18), LPS (18,31), poly I:C (31), heat-killed L. monocytogenes (29), and viruses (28), no studies proposed optimal activation protocols for stable expression of some surface molecules (such as CD40 and CD11c), necessary for maximal effectiveness of these cells in vivo and their migration to regional LNs.

In our studies, JAWSII cells were found to be MHC class I and II, and CD80 positive and exerted strong endocytic properties. The cells expressed TLR1, TLR3, and to some extent TLR4 as well as TLR9 and, accordingly, responded strongly to poly I:C and LPS by massive production of TNF- $\alpha$, IL-6, chemokine MCP-1, increased expression of MHC class I and CD80 molecules, as well as by the decreased ability of endocytosis. Altogether these results show maturation-inducing potential of poly I:C and LPS. This observation is in agreement with earlier results concerning human DC cells showing activation of monocyte-derived DCs by poly I:C (32). Recently, Navabi et al have demonstrated that poly I:C analogue (Ampligen) is effective in inducing optimal maturation of human DC in vitro (33). In contrast to high expression of TLR3, JAWSII cells expressed a moderate level of TLR4, the receptor typical for many cells of the innate immunity (20). LPS, a standard agonist of this receptor, stimulated secretion of a cytokine profile that was similar to poly I:C but, unlike poly I:C, did not influence the expression of MHC I molecules (Table I and Fig. 3). As expected, and in agreement with many previous studies investigating functions of DCs $(7,22,34)$, IFN- $\gamma$ strongly stimulated expression of CD80 and MHC molecules (Fig. 4) but production of cytokines remained unchanged. In fact, IFN- $\gamma$ enhances expression/production of proinflammatory cytokines by dendritic cells only if given before TLR agonists $(5,35)$.

Two-signal model of T-cell activation by dendritic cells does not adequately describe the requirements for the maximal induction of the adaptive immune response and a recent opinion is that a third signal is required for the generation of cell-mediated immunity and effective CTL responses, including antitumor immunity. This signal is mediated by IL-12 produced by antigen-presenting cells, including DCs, as a result of a positive feedback mechanism between activated DCs and T cells and interaction of CD40L with CD40 molecule $(5,24,32)$. In our studies, we observed increased CD40 expression on JAWSII cells after incubation with poly I:C and IFN- $\gamma$ (Fig. 5). As shown by Haase et al on the model of T-cell priming with Der p1 peptide (27), transduction of JAWSII cells with CD40 gene may lead to specific activation of naive T cells. We expect, therefore, that similar phenomenon will be elicited in our immunotherapeutic model, in which we plan to use JAWSII cells for the induction of anti-tumor immunity against melanoma cells in mice (unpublished data).

In summary, we analyzed the phenotype and some functional properties of the cells of the established immature dendritic JAWSII cell line and provided evidence that after exposure to a maturation-inducing ligands the cells can migrate to regional lymph nodes and stimulate naive $\mathrm{T}$ cells. We believe that JAWSII cells could be valuable in the investigation of DC-T cell interactions that would lead to a better understanding the rules governing induction of either tolerance or immunity. Moreover, the cells could be a useful tool for studies on the effects of pharmaceuticals and biological response modifiers in the early stages of the immune response. Our findings might be relevant for inventing therapeutic models in cancer, allergies, infectious diseases or autoimmune disorders.

\section{Acknowledgements}

The authors would like to thank Dr G. Wilczynski and Dr A. Ratajska for their help in preliminary studies concerning migration of the JAWSII cells and preparation of cryostat sections. We also thank V.L. MacKay for information on immortalization of JAWSII cells and their phenotypic profile. This work was supported by Medical University of Warsaw, Poland (grant numbers: 1M19/W2, 1M19/NM5/07) 
and by the Ministry of Science and Higher Education, Poland (grant number: N N401 011536).

\section{References}

1. Reis e Sousa C: Dendritic cells in a mature age. Nat Rev Immunol 6: 476-483, 2006.

2. Tuyaerts S, Aerts JL, Corthals J, et al: Current approaches in dendritic cell generation and future implications for cancer immunotherapy. Cancer Immunol Immunother 56: 1513-1537, 2007.

3. Bonasio R and von Andrian UH: Generation, migration and function of circulating dendritic cells. Curr Opin Immunol 18: 503-511, 2006.

4. Joffre O, Nolte MA, Sporri R and Reis e Sousa C: Inflammatory signals in dendritic cell activation and the induction of adaptive immunity. Immunol Rev 227: 234-247, 2009.

5. Macagno A, Napolitani G, Lanzavecchia A and Sallusto F: Duration, combination and timing: the signal integration model of dendritic cell activation. Trends Immunol 28: 227-233, 2007.

6. Smith CM, Wilson NS, Waithman J, et al: Cognate CD4(+) T cell licensing of dendritic cells in CD8(+) T cell immunity. Nat Immunol 5: 1143-1148, 2004.

7. Koski GK, Cohen PA, Roses RE, Xu S and Czerniecki BJ: Reengineering dendritic cell-based anti-cancer vaccines. Immunol Rev 222: 256-276, 2008.

8. Grohmann U, Bianchi R, Ayroldi E, et al: A tumor-associated and self antigen peptide presented by dendritic cells may induce $\mathrm{T}$ cell anergy in vivo, but IL-12 can prevent or revert the anergic state. J Immunol 158: 3593-3602, 1997.

9. Gabrilovich D: Mechanisms and functional significance of tumour-induced dendritic-cell defects. Nat Rev Immunol 4: 941-952, 2004.

10. Kalady MF, Onaitis MW, Emani S, Abdel-Wahab Z, Tyler DS and Pruitt SK: Sequential delivery of maturation stimuli increases human dendritic cell IL-12 production and enhances tumor antigen-specific immunogenicity. J Surg Res 116: 24-31, 2004.

11. Winzler C, Rovere P, Rescigno M, et al: Maturation stages of mouse dendritic cells in growth factor-dependent long-term cultures. J Exp Med 185: 317-328, 1997.

12. Almand B, Resser JR, Lindman B, et al: Clinical significance of defective dendritic cell differentiation in cancer. Clin Cancer Res 6: 1755-1766, 2000 .

13. Czerniecki BJ, Koski GK, Koldovsky U, et al: Targeting HER-2/ neu in early breast cancer development using dendritic cells with staged interleukin-12 burst secretion. Cancer Res 67: 1842-1852, 2007.

14. Lombardi V, Van Overtvelt L, Horiot S and Moingeon P: Human dendritic cells stimulated via TLR7 and/or TLR8 induce the sequential production of Il-10, IFN-gamma, and IL-17A by naive CD4 ${ }^{+}$T cells. J Immunol 182: 3372-3379, 2009.

15. Masterson AJ, Sombroek CC, De Gruijl TD, et al: MUTZ-3, a human cell line model for the cytokine-induced differentiation of dendritic cells from CD34+ precursors. Blood 100: 701-703, 2002.

16. Shen Z, Reznikoff G, Dranoff G and Rock KL: Cloned dendritic cells can present exogenous antigens on both MHC class I and class II molecules. J Immunol 158: 2723-2730, 1997.

17. Xu S, Ariizumi K, Caceres-Dittmar G, et al: Successive generation of antigen-presenting, dendritic cell lines from murine epidermis. J Immunol 154: 2697-2705, 1995.

18. Jorgensen TN, Haase C and Michelsen BK: Treatment of an immortalized APC cell line with both cytokines and LPS ensures effective T-cell activation in vitro. Scand J Immunol 56: 492-503, 2002.
19. MacKay VL and Moore EE: Immortalized dendritic cells US Patent. 5,648,219 dated July 15, 1997; ATCC number: CRL$11904,1997$.

20. Chen K, Huang J, Gong W, Iribarren P, Dunlop NM and Wang JM: Toll-like receptors in inflammation, infection and cancer. Int Immunopharmacol 7: 1271-1285, 2007.

21. Pulendran B: Modulating vaccine responses with dendritic cells and Toll-like receptors. Immunol Rev 199: 227-250, 2004.

22. Ueno H, Klechevsky E, Morita R, et al: Dendritic cell subsets in health and disease. Immunol Rev 219: 118-142, 2007.

23. Switaj T, Jalili A, Jakubowska AB, et al: CpG immunostimulatory oligodeoxynucleotide 1826 enhances antitumor effect of interleukin 12 gene-modified tumor vaccine in a melanoma model in mice. Clin Cancer Res 10: 4165-4175, 2004.

24. Fujii S, Liu K, Smith C, Bonito AJ and Steinman RM: The linkage of innate to adaptive immunity via maturing dendritic cells in vivo requires CD40 ligation in addition to antigen presentation and CD80/86 costimulation. J Exp Med 199: 1607$1618,2004$.

25. Mailliard RB, Wankowicz-Kalinska A, Cai Q, et al: alpha-type-1 polarized dendritic cells: a novel immunization tool with optimized CTL-inducing activity. Cancer Res 64: 5934-5937, 2004.

26. Thatcher TH, Luzina I, Fishelevich R, Tomai MA, Miller RL and Gaspari AA: Topical imiquimod treatment prevents UV-light induced loss of contact hypersensitivity and immune tolerance. J Invest Dermatol 126: 821-831, 2006.

27. Haase C, Michelsen BK and Jorgensen TN: CD40 is necessary for activation of naive $T$ cells by a dendritic cell line in vivo but not in vitro. Scand J Immunol 59: 237-245, 2004.

28. Brossart P, Goldrath AW, Butz EA, Martin S and Bevan MJ: Virus-mediated delivery of antigenic epitopes into dendritic cells as a means to induce CTL. J Immunol 158: 3270-3276, 1997.

29. Begum MD, Umemura M, Kon S, et al: Suppression of the bacterial antigen-specific $\mathrm{T}$ cell response and the dendritic cell migration to the lymph nodes by osteopontin. Microbiol Immunol 51: 135-147, 2007.

30. Pajtasz-Piasecka E, Rossowska J, Szyda A, Krawczenko A and Dus D: Generation of anti-tumor response by JAWS II mouse dendritic cells transduced with murine interleukin 12 genes. Oncol Rep 17: 1249-1257, 2007.

31. Pinchuk LM, Lee SR and Filipov NM: In vitro atrazine exposure affects the phenotypic and functional maturation of dendritic cells. Toxicol Appl Pharmacol 223: 206-217, 2007.

32. Cella M, Scheidegger D, Palmer-Lehmann K, Lane P, Lanzavecchia A and Alber G: Ligation of CD40 on dendritic cells triggers production of high levels of interleukin-12 and enhances $\mathrm{T}$ cell stimulatory capacity: T-T help via APC activation. J Exp Med 184: 747-752, 1996.

33. Navabi H, Jasani B, Reece A, et al: A clinical grade poly I:Canalogue (Ampligen) promotes optimal DC maturation and Th1-type T cell responses of healthy donors and cancer patients in vitro. Vaccine 27: 107-115, 2009.

34. Frasca L, Nasso M, Spensieri F, et al: IFN-gamma arms human dendritic cells to perform multiple effector functions. J Immunol 180: 1471-1481, 2008.

35. Napolitani G, Rinaldi A, Bertoni F, Sallusto F and Lanzavecchia A: Selected Toll-like receptor agonist combinations synergistically trigger a $\mathrm{T}$ helper type 1-polarizing program in dendritic cells. Nat Immunol 6: 769-776, 2005. 